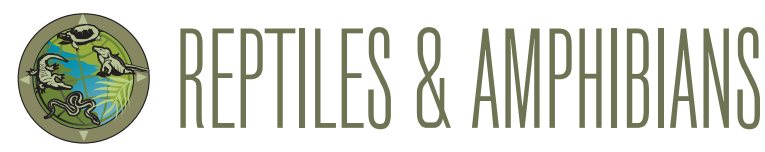

\title{
Cuban Green Anole, Anolis porcatus Gray 1840 (Squamata: Dactyloidae): Precopulatory Behavior Interrupted by Another Male
}

Luis F. de Armas

P.O. Box 4327, San Antonio de los Baños, Artemisa 38100, Cuba (luisdearmas1945@gmail.com)

$\mathrm{T}$ he Cuban Green Anole (Anolis porcatus Gray 1840), one of the most abundant and widely distributed lizards in the Cuban Archipelago (Rodriguez-Schettino 1999; Rodriguez-Schettino et al. 2013), also has been introduced into the Dominican Republic, Florida, and Curaçao (Henderson and Powell 2009; Stuart et al. 2012). This species is frequently encountered on buildings and in gardens and parks (Powell and Henderson 2008). Its reproduction in Havana Province has been described as both continuous and cyclical by Rodriguez (1982) and Sanz et al. (2005), respectively. Parmerlee et al. (1992) described interruption of copulation by a larger male in an introduced population in the Dominican Republic, but a similar event has not been documented in Cuba.

At 1602 h on 4 April 2021 in the backyard of a residence in San Antonio de los Baños, Artemisa Province, Cuba $\left(22.89347^{\circ} \mathrm{N}, 82.50978^{\circ} \mathrm{W}\right.$; elev. $75 \mathrm{~m}$ asl), while I was taking a video of precopulatory behavior of Cuban Green Anoles $2.1 \mathrm{~m}$ above the ground on the trunk of a Barbados Cherry (Malpighia punicifolia) (Fig. 1A), a second male (SVL $-65 \mathrm{~mm}$ ) suddenly approached the pair from a position no more than $2 \mathrm{~m}$ higher on the tree and, without prelude, attacked the other male (Figs. 1C-D). After approximately $3 \mathrm{sec}$, the two males (which were of comparable size) disengaged, after which the intruder twice displayed his dewlap and gaped (Fig. 1E). He immediately attacked again and bit the other male (Figs. 1F-G), which backed down and escaped, while the female moved toward the opposite side of the trunk (Fig. 1G). The intruder then left quickly (Fig. $1 \mathrm{H})$, while the agitated female remained in place. The duration of the fight was only $10 \mathrm{sec}$. During the entire sequence, the female's tail was tightly coiled around a part of the trunk (Figs. 1A-F, arrows).

I could not determine if the attacking male was defending his territory, because the territories of three or four adult males include this tree ( $4.40 \mathrm{~m}$ height $\times 3.2 \mathrm{~m}$ diameter) and I have occasionally observed disputes involving displays but without fighting. However, the behavior of the attacker appeared to be that of a resident male.

In the episode described by Parmerlee et al. (1992), the males were less aggressive and the behavior of the intruder clearly differed from that described herein. In the description of interrupted copulation of a pair of Cuban Blue Anoles (Anolis allisoni), Borroto-Páez and Reyes Pérez (2019) stated that the intruder "approached the copulating pair, moving in intervals interrupted by pauses of several seconds" and then "attacked and bit the copulating male twice." The female's behavior described herein also differed from that described in the other two incidents in that she did not escape, but remained in place and she used her tail to grasp the substrate.

\section{Acknowledgement}

Manuel Iturriaga (Institute of Ecology and Systematics, Havana) provided some references and reviewed an earlier draft of this manuscript.

\section{Literature Cited}

Borroto-Páez, R. and D. Reyes Pérez 2019. Cuban Blue Anole (Anolis allisoni) copulation interrupted by another male. Reptiles \& Amphibians 26: 115-116.

Henderson, R.W. and R. Powell. 2009. Natural History of West Indian Reptiles and Amphibians. University Press of Florida, Gainesville, Florida, USA.

Parmerlee, J.S., Jr., R. Powell, D.D. Smith, and A. Lathrop. 1992. Unusual behavior in the Cuban Green Anole, Anolis porcatus (Sauria: Polychridae). Bulletin of the Chicago Herpetological Society 27: 118.

Powell, R. and R.W. Henderson. 2008. Urban herpetology in the West Indies, pp. 87-102. In: In: J.C. Mitchell, R.E. Jung Brown, and B. Bartholomew (eds.), Urban Herpetology. Herpetological Conservation, volume 3, Society for the Study of Amphibians and Reptiles, Salt Lake City, Utah, USA.

Rodríguez, M.E. 1982. Ciclo reproductivo de Anolis porcatus (Gray, 1840) y Anolis allisoni (Barbour, 1928) de Cuba. Unpublished Diploma Thesis, Faculty of Biology, Havana University, Havana, Cuba.

Rodriguez Schettino, L. 1999. The Iguanid Lizards of Cuba. University of Florida Press, Gainesville, Florida, USA

Rodríguez Schettino, L., C.A. Mancina, and V. Rivalta. 2013. Reptiles of Cuba: Checklist and geographic distributions. Smithsonian Herpetological Information Service 144: 1-96. https://doi.org/10.5479/si.23317515.144.1.

Sanz, A., M.C. Uribe, and L.J. Guillette, J.R. 2005. Seasonal gametogenic cycles in a Cuban tropical lizard, Anolis porcatus. Journal of Herpetology 39: 443-454. https://doi.org/10.1670/160-03A.1. 

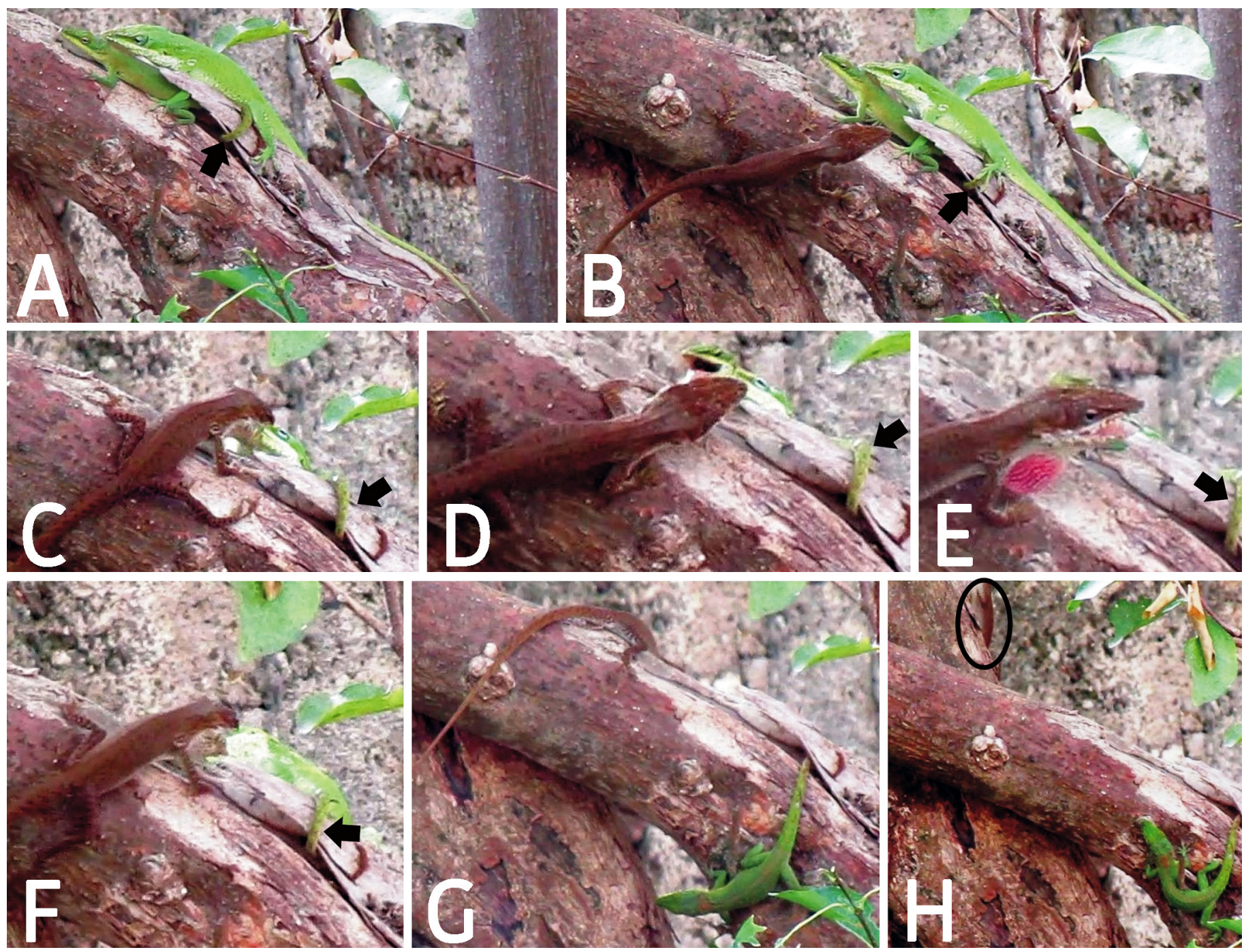

Fig. 1. Precopulatory behavior of a male Cuban Green Anole (Anolis porcatus) interrupted by another male in an urban backyard at San Antonio de los Baños, Artemisa Province, Cuba. During the prelude to mating (A) another male approaches (B) and immediately attacks the first male (C-D); after 3 sec, the males disengage and display aggressive behavior $(\mathrm{E})$; subsequently, the intruder attacks again $(\mathrm{F})$, the first male escapes, and the female moves to the opposite side of the trunk $(\mathrm{G})$ before the intruder leaves $(\mathrm{H})$ and the female remains. The entire sequence took 10 sec. Arrows in A-F indicate the location of the female's tail coiled around a part of the trunk. In $\mathrm{H}$, the intruder male is circled. Photographs are from a 48-minute video taken by the author.

Stuart, Y.E., M.A. Landestoy, D.L. Mahler, D. Scantlebury, A.J. Geneva, P.S. Van Middlesworth, and R.E. Glor. 2012. New introduced populations of the
Cuban Green Anole (Anolis porcatus) in the Dominican Republic. Reptiles \& Amphibians 19: 71-75. 